\title{
PRIMJENA KONCEPTA KRUŽNOG GOSPODARSTVA I INDUSTRIJSKE EKOLOGIJE KAO DOPRINOS ODRŽIVOM RAZVOJU I ZAŠTITI OKOLIŠA
}

UDK 338:504.06

PRIMLJENO: 31.10 .2019 .

PRIHVAĆENO: 2.7 .2020$.

Ovo djelo je dano na korištenje pod Creative Commons Attribution 4.0 International License

SAŽETAK: Industrijska ekologija bavi se promjenama industrijskih procesa i primjenom linearnih sustava koji su prikazani kao otvorena petlja gdje resursi i kapitalna ulaganja putuju kroz sustav postajući na kraju otpad, na kružne sustave odnosno zatvorenu petlju (eng. Closed-Loop) gdje se otpad upotrebljava u novim procesima. Kružno gospodarstvo je model proizvodnje i potrošnje koji uključuje ponovno korištenje, obnavljanje i recikliranje postojećih proizvoda kako bi im se produljio vijek trajanja uz istovremeno smanjenje količina otpada. Postoje različiti koncepti koji se primarno vežu s konceptom kružnog gospodarstva, a jedan od njih je od kolijevke do kolijevke (eng. "Cradle to Cradle") koncept koji po uzoru na prirodu i harmoniju ekosustava pokušava potpuno eliminirati otpad. U ovom preglednom radu, primjenom analize sadržaja relevantne znanstvene i stručne literature te dokumentacije, cilj je definirati koncepte industrijske ekologije i kružnog gospodarstva, ukazujući na prednosti koje proizlaze njihovom primjenom, kao što je minimiziranje troškova sirovina, skladištenja i odlaganja prvenstveno industrijskog otpada, s krajnjim ciljem realizacijom održivog razvoja.

Ključne riječi: Cradle-to-Cradle dizajn, industrijska ekologija, kružno gospodarstvo, održivi razvoj, zaštita okoliša

\section{UVOD}

Posljednjih godina mnogo se piše o konceptu održivog razvoja kako u svjetskoj, tako i u hrvatskoj literaturi. Odnos između čovjeka i okoliša dramatično se mijenja kroz povijest. Stupanj industrijalizacije u konstantnom je rastu, a kontinuiran rast ekonomije čini sve veći jaz između razvijenih zemalja i zemalja u razvoju. Nagli rast stanovništva posljednjih godina ugrožava različite vrste izvora te će prema procjenama UN-a do 2050. godine Zemlja imati 9,3 milijardi ljudi (Herceg, 2013.). Kao rezultat takvog globalnog rasta proizvodnje generiraju se i sve veći negativni utjecaji na okoliš. Koncept „održivi razvoj" često je kritiziran kao prilično nejasan pojam koji

*Sanja Miketić-Curman, mr. sig., (sanja.miketic-curman@ dunapack-packaging.com), Valoviti papir Dunapack d.o.o., Trebež 2 , 49210 Zabok. je teško operacionalizirati (Cifrić, 2002.:49 prema Schellnhuber, 1998.). Postoji više definicija što je održivi razvoj, a najpoznatija i najčešće upotrebljavana je ona navedena u izvješću UN-ove Komisije za okoliš i razvoj iz 1987. godine prema kojoj je to razvoj kojim se zadovoljavaju potrebe današnjih naraštaja, a da se pritom ne ugrožava mogućnost budućih naraštaja u zadovoljavanju njihovih potreba. Kada se govori o ciljevima održivog razvoja, oni se temelje na 3 važna elementa, i to: 1) gospodarskoj učinkovitosti, odnosno ekonomskom razvoju, gdje ekonomski održiv razvoj pretpostavlja ostvarivanje gospodarskog razvoja i učinkovitosti; 2) socijalnom napretku, odnosno društvenoj odgovornosti koja se postiže ostvarivanjem zadovoljavajućeg stupnja životnog standarda i 3) odgovornosti prema okolišu, gdje ekološka održivost podrazumijeva razvoj koji poštuje prihvatni kapacitet okoliša (Herceg, 2013.:256). 
Šezdesetih i sedamdesetih godina prošlog stoljeća počinje se javljati bojazan da gospodarski rast te razvojni konzumerizam i s njim povezani zahtjevi životnog stila narušavaju ekološku ravnotežu, ekonomsku stabilnost i sigurnost planeta (Blewitt, 2017.:22). Ekspertna organizacija ekonomista pod nazivom "Rimski klub" 1972. godine objavljuje prijelomnu studiju "Granice rasta" kojom upozorava da postoje granice ekonomskog rasta koji se temelji na iskorištavanju neobnovljivih prirodnih izvora te da postoje razne vrste onečišćenja tla, rijeka i zraka kao popratnih pojava u proizvodnim procesima i uporabi novih tehnologija (Blewitt, 2017.).

\section{KRUŽNO GOSPODARSTVO}

Gospodarstvo se zasniva na modelu kontinuiranog rasta koje zahtijeva redovitu opskrbu prirodnim resursima. Primjenom linearnog gospodarstva, koji je najčešći model proizvodnje, iscrpljuju se prirodni resursi i stvara se otpad koji zagađuje okoliš. Stoga je nužno primijeniti model koji osigurava održivo gospodarenje resursima, smanjuje pritisak na okoliš, povećava konkurentnost i inovativnost, što su ciljevi kružnog gospodarstva. Postoje višestruki pristupi i aktivnosti koji se koriste u kružnom gospodarstvu, a oni se razlikuju prema definicijama i zemljama u kojima se razmatraju. No, oni uključuju ponovnu uporabu, popravak, recikliranje, ekodizajn, industrijsku ekologiju, održivu opskrbu i odgovornu potrošnju, odnosno mnoštvo pojmova koji pokazuju da se definicija kružnog gospodarstva još nije potpuno stabilizirala (GaIlaud i Laperche, 2016.). Eksperimenti koji su se odnosili na kružnu ekonomiju razvijali su se u raznim dijelovima svijeta početkom 2000-ih godina. Međutim, kružno gospodarstvo pojam je koji se spominje u raznim disciplinama 70-ih godina prošlog stoljeća. Prvi službeni dokument koji govori o zaokretu gospodarskog razvoja prema konceptu kružnog gospodarstva objavljen je 2012. godine pod nazivom Towards Circular Economy gdje je istaknut golem potencijal kružnog gospodarstva u stvaranju financijskih ušteda (Tišma $i$ sur., 2017.). Na slici 1 prikazana je usporedba primjene modela linearnog naspram kružnog gospodarstva.

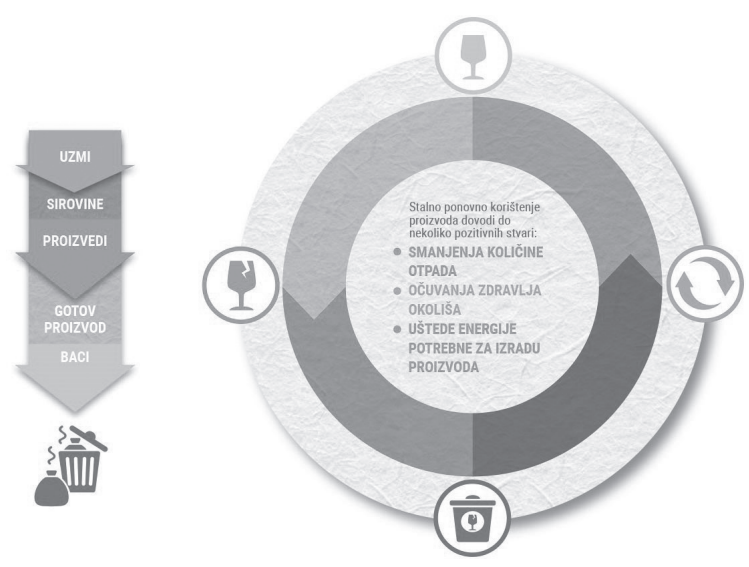

Slika 1. Usporedba linearnog i kružnog gospodarstva Figure 1. The comparison of linear and circular economy

\section{INDUSTRIJSKA EKOLOGIJA}

Industrijska ekologija je mlada, ali rastuća višedisciplinarna grana znanosti koja udružuje aspekte konstruiranja, ekonomije, sociologije, toksikologije i prirodnih znanosti. Pojam se proširio 1989. godine objavom članka autora Roberta Froscha i Nocholasa E. Gallopoulosa u časopisu Scientific American u kojem su autori postavili pitanje zašto se ne bi industrijski sustavi ponašali kao ekosustav u kojem otpad jedne vrste može biti resurs drugoj vrsti? Zašto ne bi izlaz jedne industrije bio ulaz drugoj smanjujući tako uporabu sirovina, zagađenje i troškove za zbrinjavanje otpada. Na taj bi način industrija oponašala procese u prirodi u kojoj je otpad jedne vrste ujedno resurs druge vrste, smanjujući na taj način uporabu sirovina i utjecaj onečišćenja stvarajući istodobno uštede u procesu (Bačun i sur., 2012.:113). U industrijskoj ekologiji, industrija se ne promatra odvojeno od svojeg okruženja, već se na nju gleda kao na dio sustava s kojim je povezana transakcijama, aktivnostima i utjecajem. Ovakav cjelovit pogled ukida otpad kao kategoriju jer on predstavlja ulazne resurse za novu proizvodnju. Stoga je svrha primjene industrijske ekologije iskorištavanje otpada, na način da je otpad iz jednog procesa sirovina u drugom, iz čega se razvio koncept ekoindustrijskih parkova (EPI) odnosno industrijske simbioze (Omar, El-Haggar, 2017.). Jedan od prvih ekoindustrijskih parkova u svijetu je industrijski park u gradu Kalundborgu u Danskoj. To je prva svjet- 
ska industrijska simbioza koja se razvila tijekom proteklih 50 godina. Suradnja među tvrtkama u simbiozi osigurava obostranu korist, ekonomsku i ekološku. Tako se u spomenutom ekoindustrijskom parku može naći poveznica nusprodukata i otpadne topline između brojnih subjekata kao što su velike elektrane, rafinerije ulja, farmaceutska postrojenja, tvornice gipsanih ploča, proizvođači enzima i samoga grada. Prema dostupnim podacima, tamošnja simbioza smanjuje emisiju $\mathrm{CO}_{2}$ za otprilike 275.000 tona godišnje i štedi oko 3 milijuna kubičnih metara vode godišnje.

Industrijska ekologija vrlo je brzo percipirana kao lokalni i regionalni razvojni alat. Autori GaIlaud i Laperche (2016.) nabrojali su neke od njezinih pozitivnih učinaka na društvo, gospodarstvo i okoliš:

a) otpad proizveden u jednoj industriji predstavlja ulazni materijal za drugu, smanjujući na taj način troškove sirovina

b) smanjeni otpad znači niže troškove odvoza otpada

c) otpad dobiva ekonomsku vrijednost, povećavajući dobit

d) potencijal za otvaranje novih radnih mjesta stvaranjem novih tvrtki i

e) smanjene emisije znači manju potrebu za odvajanjem industrijskih područja od stambenih zona.

\section{Pristup Cradle to Cradle i ekodizajn proizvoda}

Cilj pristupa Cradle to Cradle (C2C) odnosno "od kolijevke do kolijevke" (Omar, El-Haggar, 2017.) stvaranje je cikličkog procesa kojem je glavni cilj smanjenje otpada, umjesto linearnog koji je specifičan za pristup Cradle to Grave, odnosno „od kolijevke do groba“. Međutim, pristup "od kolijevke do kolijevke" ide korak dalje i pokušava potpuno eliminirati otpad. Prema uzoru na prirodu i harmoniju ekosustava, sve ono što danas radimo i stvaramo trebalo bi imati svoj prirodan tijek, mogućnost novih pretvorbi te, istovremeno, osiguravati doprinos, boljitak i blagostanje svakoj zajednici. Ideja djelovanja, življenja i proizvodnje "od kolijevke do kolijevke", umjesto "od kolijevke do groba" kao glavnoga načela današnje civilizacije, misao je vodilja dvojice autora Williama McDounagha i Michaela Braungarta
(2002.) koji su bili ključni u dizajniranju i razvoju sadašnjeg Cradle to Cradle koncepta. Način na koji je proizvod dizajniran ukazuje na njegov utjecaj na okoliš. Otpad se stvara, ali, kao i u prirodi, koristi se kao hrana za novi proces. Koristeći prirodu kao model, proizvodi i sustavi osmišljeni su kako bi ponovno vratili zastarjele materijale u sustav i zatim ih ponovno iskoristili. Opet se radi o sustavu zatvorene petlje jer se otpad ne odbacuje. Prema McDonoughu i Braungartu (2002.), u procesu "od kolijevke do kolijevke", otpadni proizvodi su u osnovi hranjive tvari za drugi proces. Na slici 2 prikazan je ciklus zatvorene petlje protoka materijala koji ima benefit na način da će smanjiti količinu nastalog otpada i tako očuvati okoliš, istovremeno osiguravajući stalnu dostupnost materijala visoke kvalitete.

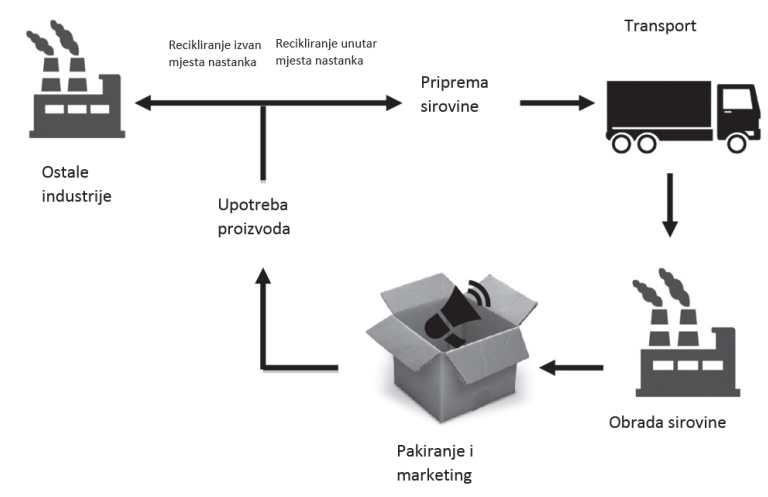

Slika 2. Pristup Cradle-to-Cradle („od kolijevke do kolijevke")

Figure 2. Cradle-to-cradle approach

Proizvodni sustav Cradle to Cradle podržava filozofiju da nikakav materijal neće biti otpad na kraju ciklusa, odnosno pristupom se promiče dizajn proizvoda u kojem se sastavni materijali mogu koristiti za drugi proizvod gdje uvijek postoji zatvorena petlja.

Svi proizvodi imaju određeni negativan utjecaj na okoliš tijekom ciklusa trajanja, od korištenja sirovina i energije, preko proizvodnje, pakiranja, transporta, odlaganja i recikliranja. Negativnim utjecajima smatraju se energija potrošena prilikom proizvodnje, otpadni materijal i otrovne supstance oslobođene tijekom ekstrakcije resursa, prerade i transporta, zatim energija koju koristi proizvod tijekom svojeg ciklusa trajanja te otpadni proizvodi i energija potrebna za zbrinjavanje proizvoda. Prema Europskoj komisiji 80 \% svih 
utjecaja na okoliš povezanih s nekim proizvodom određeno je već tijekom faze dizajna, stoga bi primjenom načela ekodizajna u početnim fazama dizajna proizvoda, potrošena ili izgubljena energija tijekom cijelog ciklusa trajanja proizvoda trebala biti znatno smanjena.

Ekodizajn označava dizajniranje proizvoda s težištem utjecaja proizvoda na okoliš tijekom njegovog cijelog ciklusa trajanja. Proizvod ekodizajna odražava filozofiju koncepta „od kolijevke do kolijevke", čime se osigurava da se u cijelom procesu ne stvara nikakav otpad. Oponašajući životne cikluse u prirodi, ekodizajn je temeljni koncept u postizanju istinski kružnog gospodarstva čijim se pristupom u proizvodnji roba i usluga zadovoljavaju potrebe kupaca, istovremeno koristeći minimalnu razinu resursa s minimalnim utjecajem, kako na okoliš, tako i na društvo.

Na primjeru jedne tvornice u Hrvatskoj ${ }^{1}$ koja se bavi proizvodnjom valovitog kartona i ambalaže od valovitog kartona može se u njihovom poslovanju utvrditi primjena koncepta Cradle to Cradle. Naime, sav proizvodni asortiman tvornice u potpunosti je obnovljiv te se može u cijelosti iskoristiti kao sirovina za ponovnu izradu papira, što je i praksa promatrane tvornice. Stoga se sav otpadni papir i karton koji nastaje tijekom proizvodnog procesa preša, balira i odvozi na reciklažu u tvornicu za recikliranje.

Recikliranje papira jedan je od najstarijih oblika recikliranja. Koliko ima veliku ulogu u očuvanju okoliša, govori podatak da su za proizvodnju jedne tone papira potrebna 4 stabla, 200.000 litara vode i $4600 \mathrm{kWh}$ energije, dok za proizvodnju jedne tone recikliranog papira nije potrebno niti jedno stablo, već 160 litara vode i 2400 kWH energije. Agencija za zaštitu okoliša (EPA) dokazala je da recikliranje papira dovodi do $35 \%$ manjeg zagađenja vode i $74 \%$ manjeg zagađenja zraka u odnosu na primarnu proizvodnju papira ${ }^{2}$.

\footnotetext{
${ }^{1}$ Autorica je doktorantica na poslijediplomskom doktorskom studiju sociologije Filozofskog fakulteta u Zagrebu. Pod mentorstvom prof. emeritusa Ognjena Čaldarović izradila je doktorski rad koji se bavi istraživanjem učinaka tvornice u lokalnoj zajednici - analizirajući između ostalog i koncept kružnog gospodarenja odnosno „Cradle to Cradle" pristup u jednoj tvornici u Hrvatskoj. Rad je trenutno u fazi ocjenjivanja od strane imenovanog povjerenstva.

${ }^{2}$ Dostupno na: http://rcco.hr/recikliranje-papira/pristupljeno: 25.10.2019.
}

Promatrana tvornica sudjelovala je 2015. godine u projektu koji se odnosio na analizu životnog ciklusa proizvoda iz vlastitog proizvodnog asortimana u svrhu mjerenja emisije ugljičnog dioksida $\left(\mathrm{CO}_{2}\right)$ u proizvodnom procesu. Projekt je financiran iz fondova Europske unije, namijenjen prvenstveno proizvodnim tvrtkama čije je sudjelovanje u projektu bilo besplatno. Osnovni cilj projekta bio je upoznati tvrtke s pojmovima ekodizajna, analize procjene životnog ciklusa proizvoda (poznatim pod skraćenicom LCA analiza) i karbonskog otiska proizvoda, pojmova koji se odnose na utjecaj proizvoda na okoliš kroz njegov cijeli vijek trajanja. Tvornica je izabrala jedan proizvod iz vlastitog proizvodnog asortimana te, uz pomoć tima za provedbu projekta, izradila karbonski otisak tog proizvoda primjenom Ecodesign+alata u mjerenju emisije $\mathrm{CO}_{2}$. Pojednostavljeno, radi se o utjecaju proizvoda na emisije u okoliš za cijeli njegov vijek trajanja (izrada materijala, transport, proizvodnja poluproizvoda i dijelova, montaža gotovog proizvoda, eksploatacija i odlaganje proizvoda čiji je vijek trajanja završen), izražen kroz ekvivalent emisije $\mathrm{CO}_{2}$ kao najzastupljenijeg stakleničkog plina. Iz dobivenih rezultata uočeno je da proizvod analiziran tijekom cijelog vijeka trajanja, u fazi korištenja i na kraju ciklusa nema gotovo nikakav utjecaj na stvaranje emisija stakleničkih plinova, odnosno ugljičnog dioksida.

Općenito, tvrtke svoje rezultate mjerenja najčešće koriste u marketinške svrhe. Isto tako, rezultat može (i ne mora) utjecati na daljnji ekodizajn proizvoda (odmah ili u budućnosti) čiji će rezultat biti manji karbonski otisak. Cilj je EU-a, na koji se obvezala i Hrvatska, do 2020. godine smanjiti ukupnu emisiju $\mathrm{CO}_{2}$ za $20 \%$. Očekuje se da će ekodizajn proizvoda utjecati na povećanu konkurentnost tvrtke koja ga primjenjuje, poboljšati imidž tvrtke na tržištu te da će biti važan argument kod apliciranja sredstava iz fondova EU-a. Prema provedenim istraživanjima, ekodizajn ne predstavlja samo skup mjera kojima se postiže smanjen utjecaj na okoliš, već predstavlja i poslovnu politiku tvrtke koja u većini slučajeva pridonosi rastu profitabilnosti pa je s te strane naročito interesantan za primjenu.

\section{ZAKONSKI OKVIR}

Za prelazak na kružno gospodarstvo nužan je završetak programa učinkovitog korištenja resursa 
u sklopu Europske strategije za pametan, održiv i uključiv rast (Strategija Europa 2020.). Kao jedan od tri osnovna prioriteta razvoja Europske unije, ova desetogodišnja razvojna strategija predlaže održiv rast, odnosno promicanje ekonomije koja učinkovitije iskorištava resurse, zelenija je i konkurentnija. Europska komisija u prosincu 2015. godine donijela je novi Paket o kružnom gospodarstvu koji uključuje zakonodavne prijedloge u području gospodarenja otpadom i akcijski plan kojim se određuju konkretne aktivnosti s jasnim ciljevima smanjenja otpada u smjeru provedbe "Closing the loop" pristupa za sve faze ciklusa trajanja proizvoda. Za navedene aktivnosti izdvojena su i sredstva iz europskih strukturnih i investicijskih fondova.

U svrhu poticanja provedbe aktivnosti sprečavanja nastanka otpada, kao najučinkovitijeg i najodrživijeg načina korištenja resursa, sve zemlje članice Europske unije, pa tako i Republika Hrvatska, dužne su izraditi Plan sprečavanja nastanka otpada. Stoga je Republika Hrvatska svoje zakonodavstvo uskladila s pravnom stečevinom EU-a kroz odredbe Zakona o održivom gospodarenju otpadom, odnosno Planom gospodarenja otpadom za razdoblje 2017.-2022. godine. Prema navedenim propisima, sprečavanje nastanka otpada podrazumijeva mjere poduzete prije nego neka tvar, materijal ili proizvod postane otpad, sa svrhom smanjenja količine otpada uključujući ponovnu uporabu proizvoda i produljenje njegova vijeka trajanja, smanjenje negativnih utjecaja nastalog otpada na okoliš i ljudsko zdravlje te smanjenje sadržaja opasnih tvari u materijalima i proizvodima.

\section{ZAKLJUČAK}

Dugi niz godina primjena linearnog modela gospodarstva prema načelu „Uzmi - iskoristi - odbaci" proizvela je niz negativnih učinaka kako na okoliš tako i na ljudsko zdravlje. Stoga je prijelaz na model kružnog gospodarenja nužan, za što se odlučuje sve više tvrtki, što pokazuju primjerima dobre prakse. Međutim, koji bi bili mogući razlozi otežanog prihvaćanja primjene koncepata industrijske ekologije i kružnog gospodarstva? Pojedini industrijski poduzetnici, naročito u manjim ili srednje velikim tvrtkama, nemaju mogućnosti ili sredstava realizacije navedenih koncepata spomenutih u ovom radu. lako je poruka "da se sprečavanje zagađivanja isplati“, pojedine tvrtke i dalje prave ekonomsku računicu koliko troškovi čišće tehnologije premašuju korist od nje (Carter, 2004.:241). No, upravo zbog koristi koju primjena kružnog gospodarstva (ili cirkularne ekonomije, pojam koji se također koristi) ima na okoliš i gospodarstvo treba inzistirati na njihovoj primjeni. Njihova glavna prednost je minimiziranje troškova sirovina, prijevoza, skladištenja i odlaganja otpada, kao i troškova obrade otpada u sirovinu. Postoji podatak da se primjenom koncepta kružnog gospodarstva može smanjiti emisija štetnih plinova u atmosferu za $70 \%$ do $2030^{3}$. godine. S obzirom na činjenicu da je globalno zatopljenje gorući problem današnjice, svakako fokus i dalje treba biti na primjeni modela kružnog gospodarstva kako globalno, tako i na lokalnoj razini, a sve u cilju osiguranja održivog razvoja i zaštite okoliša.

\section{LITERATURA}

Azapagić, A., Clift, R., Perdan, S.: Sustainable Development in Practice: Case Studies for Engineers and Scientists, John Wiley \& Sons, New York 2004.

Bachman, B. J., Acharya, S. P., Baumann, M. H., Bashyal, S.: Corporate Sustainability Practices in the Plastics Industry, Polimeri, 35, 2014., 1-2, 25-28.

Bačun, D., Matešić, M., Omazić, M. A.: Leksikon održivog razvoja, Hrvatski poslovni savjet za održivi razvoj, Zagreb, 2012.

Blewitt, J.: Razumijevanje održivog razvoja, Naklada Jesenski i Turk, Zagreb, 2017.

Burchart-Korol, D.: Significance of environmental life cycle assessment (LCA) method in the iron and steel industry, Metalurgija, 50, $2001 .$, 3, 205-208.

Cao, H., Zhang, J., Luo, N., Zhang, Z.: Industrial sustainable development level in China and its influencing factors, Zbornik radova Ekonomskog fakulteta u Rijeci, 33, 2015., 2, 181-205.

\footnotetext{
${ }^{3}$ Dostupno na: https://www.theguardian.com/sustainablebusiness/2015/apr/15/circular-economy-jobs-climate-carbonemissions-eu-taxation, pristupljeno: 5.10.2019..
} 
Carter, N.: Strategije zaštite okoliša: ideje, aktivizam, djelovanje, Barbat, Zagreb, 2004.

Cifrić; I.: Okoliš i održivi razvoj: ugroženost okoliša i estetika krajolika, Hrvatsko sociološko drušvo, Zavod za sociologiju Filozofskog fakulteta Zagreb, 2002.

Cizler, J.: Urban regeneration effects on industrial heritage and local community - Case study: Leeds, UK, Sociologija i prostor, 50, 2012., 2, 223-236.

Cone, J.D., Hayes, S.C.: Environmental Problems/Behavioral Solutions, Cambridge University Press, Cambridge, 1985.

Čaldarović, O.: Sociologija i održivi razvoj, Socijalna ekologija, 2, 1993., 1, 1-18.

Čaldarović, O., Škanata, D.: Laičko i ekspertno poimanje tehnoloških rizika, Socijalna ekologija, 4, 1995., 4, 361-386.

Društvena odgovornost poduzeća (DOP), dostupno na: http//www.dop.hr, pristupljeno: 16.9.2019.

Eko d.o.o. za gospodarenje otpadom Zadarske županije, dostupno na: http://www.zatostovolimzadar.hr/gospodarenje_otpadom01.php/, pristupljeno: 1.10.2019

Epstein, M. J., Rejc Buhovac, A.: Making Sustainability Work: Best Practices in Managing and Measuring Corporate Social, Environmental, and Economic Impacts, Berrett-Koehler Publishers, Inc. San Francisco, 2014.

Europska komisija, dostupno na: https:// ec.europa.eu/environment/circular-economy/index_en.htm/, pristupljeno: 1.10.2019.

Europski parlament, dostupno na: https:// www.europarl.europa.eu/news/hr/headlines/ economy/20151201STO05603/kruzno-gospodarstvo-definicija-vrijednosti-i-korist, pristupljeno: 1.10.2019.

Fond za zaštitu okoliša i energetsku učinkovitost, dostupno na: http://www.fzoeu.hr/hr/zastita_okolisa/odrzivi_razvoj/kruzno_gospodarstvo/, pristupljeno: 1.10.2019.
Gallaud, D., Laperche, B.: Circular Economy, Industrial Ecology and Short Supply Chain, ISTE Ltd., London, 2016.

Herceg, N.: Okoliš i održivi razvoj, Synopsis, Zagreb, 2013.

Kalanj, R.: Sociologija razvoja i održivi razvoj, Socijalna ekologija, 2, 1993., 3, 407-418.

Matešić, M. Principi održivog razvoja u strateškim dokumentima Republike Hrvatske, Socijalna ekologija, 18, 2009., 3-4, 323-339.

McDonough, W., Braungart, M.: Cradle to Cradle: Remarking the Way We Make Things, North Point Press, New York, 2002.

Ministarstvo zaštite okoliša i energetike, Europa 2020, Europska strategija za pametan, održiv i uključiv rast, dostupno na: https://mzo. gov.hr/UserDocsImages//dokumenti/EUfondovi/ OPKK_2014-2020/, pristupljeno: 5.10.2019.

Omar, H., El-Haggar, S.: Sustainable Industrial Community, Journal of Environmental Protection, 8, 2017., 3, 301-318.

Omazić, A. i sur.: Zbirka studija slučaja društveno odgovornog poslovanja, Hrvatski poslovni savjet za održivi razvoj, Zagreb, 2012.

Pupavac, D.: Održivi razvoj - novo lice ekonomije, Socijalna ekologija, 24, 2015., 2-3, 103124.

Sanyé-Mengual, E., García Lozano, R.: Assessment of Carbon Footprint in Different Industrial Sectors, Springer-Verlag Singapur, 2014., Volume 1.

Tišma, S., Boromisa A-M., Funduk, M., Čermak; H.: Okolišne politike i razvojne teme, Alinea, Zagreb, 2017.

Todkari G.U.: Role of Co-operative Sugar Factories in Rular Development: A case study of Damaji SugarFactory, International Journal of Agriculture Sciences, 4, 2012., 1, 169-171.

Žeravica, D.: Kružna ekonomija, diplomski rad, Fakultet ekonomije i turizma "dr. Mijo Mirković", Pula, 2017. 


\section{IMPLEMENTING THE CONCEPT OF CIRCULAR ECONOMY AND INDUSTRIAL ECOLOGY AS A CONTRIBUTION TO SUSTAINABLE DEVELOPMENT AND ENVIRONMENT PROTECTION}

SUMMARY: Industrial ecology focuses on the transformation of industrial processes from the linear systems, shown as an open-loop type where resources and capital investments move through the system ending as waste at the end, to the circular, i.e. closed-loop systems, where the resulting waste is used in new processes. Circular economy is a model of production and consumption that involves re-use, restoration, and recycling of existing products in order to extend their useful life and to reduce the amount of waste. There are a number of different concepts relating to the basic concept of circular economy, one of those being 'cradle-to-cradle' concept which imitates nature and the harmony of ecosystems in the attempt to completely eliminate waste. The paper analyzes the relevant scientific literature with the objective to formulate the concepts of industrial ecology and circular economy and stresses the advantages of their implementation, such as resource cost minimization, easier storage and disposal, in particular industrial disposal, with the end goal of achieving sustainable development.

Key words: cradle-to-cradle design, industrial ecology, circular economy, sustainable development, environment protection

Subject review Received: 2019-10-31

Accepted: 2020-07-02 